This item was submitted to Loughborough's Research Repository by the author.

Items in Figshare are protected by copyright, with all rights reserved, unless otherwise indicated.

\title{
Mathematical modelling and experimental validation of a novel periodic flow crystallization using MSMPR crystallizers
}

PLEASE CITE THE PUBLISHED VERSION

http://dx.doi.org/10.1002/aic.15510

\section{PUBLISHER}

(c) American Institute of Chemical Engineer. Published by Wiley

\section{VERSION}

AM (Accepted Manuscript)

\section{PUBLISHER STATEMENT}

This work is made available according to the conditions of the Creative Commons Attribution-NonCommercialNoDerivatives 4.0 International (CC BY-NC-ND 4.0) licence. Full details of this licence are available at: https://creativecommons.org/licenses/by-nc-nd/4.0/

\section{LICENCE}

CC BY-NC-ND 4.0

\section{REPOSITORY RECORD}

Su, Qinglin, Chris Rielly, Keddon A. Powell, and Zoltan Nagy. 2016. "Mathematical Modelling and Experimental Validation of a Novel Periodic Flow Crystallization Using MSMPR Crystallizers". Loughborough University. https://hdl.handle.net/2134/22895. 


\title{
Mathematical modelling and experimental validation of a novel
}

\section{periodic flow crystallization using MSMPR crystallizers}

\author{
Qinglin $\mathrm{Su}^{1 *}$, Keddon A. Powell ${ }^{1,2}$, Chris D. Rielly ${ }^{1}$, Zoltan K. Nagy ${ }^{1,3 *}$ \\ 1 EPSRC Centre in Continuous Manufacturing and Crystallisation at the Department of \\ Chemical Engineering, Loughborough University, Leicestershire, LE11 3TU, UK; \\ 2 Technology Innovation Centre, University of Strathclyde, Glasgow, Lanarkshire, G1 1RD, UK; \\ 3 School of Chemical Engineering, Purdue University, West Lafayette, IN. 47907, USA \\ *su130@purdue.edu; znagy@purdue.edu
}

\begin{abstract}
The challenges of insufficient residence time for crystal growing and transfer line blockage in conventional continuous MSMPR operations are still not well addressed. Periodic flow crystallization is a novel method whereby controlled periodic disruptions are applied to the inlet and outlet flows of an MSMPR crystallizer in order to increase its residence time. A dynamic model of residence time distribution in an MSMPR crystallizer was first developed to demonstrate the periodic flow operation. Besides, process models of periodic flow crystallizations were developed with an aim to provide a better understanding and improve the performance of the periodic flow operation, wherein the crystallization mechanisms and kinetics of the glycine-water system were estimated from batch cooling crystallization experiments. Experiments of periodic flow crystallizations were also conducted in single- / three-stage MSMPR crystallizers to validate the process models and demonstrate the advantages of using periodic flow operation in MSMPR stages.
\end{abstract}

Keywords: Mathematical Modelling; MSMPR; Periodic Flow Crystallization; State of Controlled Operation; Continuous 


\section{Introduction}

Crystallization is one of the most important unit operations for separation and purification of nearly $90 \%$ of organic molecules in the pharmaceutical and fine chemical sectors. Traditionally, batch crystallization has been adopted to adjust to the stringent regulations in product quality and to the flexible demands of the market. However, rising market competitiveness due to patent expiration and the need to reduce manufacturing costs have now driven the future of pharmaceutical industries towards continuous manufacturing, which have potentials for improvements in quality control, equipment footprint, and energy and labour costs, and so on. ${ }^{1,2}$

In the past decade, continuous manufacturing and crystallization has been a highly active research field, as part of the campaign aimed at developing the next generation technologies for the pharmaceutical and fine chemical industries. ${ }^{3,4}$ Generally, there are two types of continuous crystallizers that are most investigated, viz., the tubular and the stirred-tank designs. ${ }^{5}$ Regardless of recycling, these two designs help to achieve idealised flow patterns, namely the plug-flow ${ }^{6}$ and the mixed-suspension mixed-product removal (MSMPR) operations. ${ }^{7}$ Derivatives of these two designs have resolved some of the practical concerns related to the continuous crystallization, such as the use of: (1) a continuous oscillatory baffled crystallizer (COBC) to deal with the sedimentation of crystals at low through-flow Reynolds number in a straight tube; ${ }^{8}(2)$ a slug-flow crystallizer design wherein liquid and gas are introduced into one end of the tube to spontaneously generate alternating slugs of liquid and gas to generate large uniform crystals. $^{9}$ Other examples include: (3) the multisegment multi-addition plug-flow crystallizer (MSMA-PFC) to tackle problems with supersaturation control ${ }^{1,10,11}$ or fines dissolution along the tube; ${ }^{12}$ (4) cascaded multi-stage continuous MSMPR crystallizers to enhance the product yield; ${ }^{13,14,15}$ (5) a continuous 
MSMPR crystallizer with a fines trap and a product classifier to achieve a high production rate and a low polydispersity of the crystals; ${ }^{16}$ (6) similar work was also reported of using an “inverted” product classifier unit in a modified continuous MSMPR crystallizer, wherein small crystals are withdrawn as product, and larger crystals recycled to a dissolver. ${ }^{17}$

However, one of the important issues for these two designs, in terms of the material residence time, has often been the concern for chemical engineers. For example, although a narrow residence time distribution could be achieved, a relatively long tube is necessary for slow growing crystals to achieve sufficient residence time and to reach a desired particle size for tubular crystallizers. What's more, the long tube design also makes difficult the delicate control of supersaturation by either multi-section jacket cooling or multi-addition of antisolvent. $^{10,11,12,18}$ In contrast, the broaden residence time distribution of continuous MSMPR operation adversely affects the critical quality attributes of the final products, e.g. by broadening the crystal size distribution (CSD). And to extend the material residence time, large-scale MSMPR crystallizer have to be implemented, in which the scaling up of a stirred tank will impose another problem of the slurry mixing uniformity. ${ }^{19}$ Hence, one of the objectives of our work is trying to tailor the residence time distribution in MSMPR crystallizers to enhance the quality by design (QbD) paradigm shift, i.e., quality assured by better product and process understanding with the help of mathematical modelling, in the pharmaceutical and fine chemical manufacturing sectors.

Commonly, an MSMPR crystallization is operated with continuous feeding the solution to and withdrawing the slurry from the crystallizer tank, viz., the continuous flow MSMPR crystallization. For a given operating volume, it is necessary to reduce the net inlet and outlet stream flow rates in order to obtain enough residence time for the crystals to grow, but this approach often leads to transfer line fouling and blockage. Periodic flow operation of an MSMPR crystallizer is a novel operation whereby periodic disruptions are applied to the inlet 
and outlet flows with an aim to retain the slurry in the crystallizer ${ }^{20}$. In such way, the residence time distribution can then be manipulated by having a tuneable holding time within each periodic cycle, which, for example, is able to significantly increase the mean residence time for crystallization systems without further broadening its distribution. There are also benefits from the intermittently operated feeding and withdrawing streams: increasing these flow rates over short duration, helps to alleviate the usual transfer line fouling and blockage problems. Notably, the periodic flow crystallization is a hybrid of batch and continuous crystallization, and if the transient effects caused by periodic flow are controlled within narrow limits in the design space, then the final crystal product attributes will be maintained in a "state of controlled operation", as required by FDA regulations. Comparisons of the batch, continuous, and periodic operations of a stirred tank crystallizer have been summarised in Table 1. In addition, the periodic flow crystallization can also be applied to cascaded multi-stage MSMPR crystallizers to facilitate the controlled nucleation and extended crystal growth.

In this study, a dynamic model for residence time distribution in an MSMPR crystallizer was first developed to demonstrate the concept of periodic flow operation. Flowsheet process models were then developed for periodic flow crystallization processes using single- or threestage MSMPR crystallizers in order to provide a better understanding and improve the performance of this "state of controlled operation". The modelling framework was based on the Process Systems Enterprise's gCRYSTAL platform, wherein crystallization mechanisms and kinetics of the model glycine-water system were estimated from batch cooling crystallization experiments equipped with process analytic tools (PATs) for solute concentration and crystal size measurements. The models were shown to agree well with the experimental observations from the periodic flow crystallization process, which would contribute to the optimal design and control of periodic flow operations in the future. 


\section{Materials and experiments}

Glycine (GLY, $\geq 99 \%$ in purity, Sigma Aldrich, UK) dissolved in deionized water $\left(\mathrm{H}_{2} \mathrm{O}\right)$ was used as a model cooling crystallization system in this work, with experiments of batch, continuous, and periodic flow crystallizations conducted in bench-scale stirred tank crystallizers. The following briefly summarises the experimental procedures. ${ }^{21}$

Firstly, the metastable zone width (MSZW) of GLY was determined by the polythermal method, in which unseeded batch cooling crystallization experiments were carried out, with initial concentrations ranging from 0.2800 to 0.4223 (g GLY/g $\mathrm{H}_{2} \mathrm{O}$ ), and with constant cooling rates from 0.1 to $0.7{ }^{\circ} \mathrm{C}$ per minute. The solubility of GLY was obtained from literature data. ${ }^{22}$ The MSZW can be thought as a reflection of crystallization mechanism and kinetics, viz., nucleation and crystal growth, of a crystallization system. Hence, it has been widely used for crystallization kinetic studies, for example, Mitchell and his colleagues estimated the primary nucleation and crystal growth kinetics for paracetamol and ethanol crystallization system. ${ }^{23,24}$ In this study, however, not only the MSZW data, but the whole courses of various batch cooling crystallizations were used to estimate the crystallization kinetics, including primary nucleation, secondary nucleation, and crystal growth. A population balance based process model ${ }^{25,26}$ was developed and applied to estimate the kinetic parameters from four representative batch experiments, as shown in Table 2.

Furthermore, a series of periodic flow crystallization experiments using single or cascaded three-stage MSMPR crystallizers were conducted to independently validate the crystallization kinetics estimated from the above batch experiments. The block diagrams of the experimental setups are shown in Figure 1. Feeding solutions for the periodic flow operations were first prepared with a saturated concentration of $0.2278 \pm 0.001$ (g GLY/g $\mathrm{H}_{2} \mathrm{O}$ ) at $20{ }^{\circ} \mathrm{C}$ in a 5 Litre vessel. They were then cooled to $19{ }^{\circ} \mathrm{C}$ and seeded with $2.5 \%$ 
(28.47 g GLY) of sieved crystals and held for a period of 30 min to allow crystals to heal; the supersaturation ratio of the feed suspension was maintained at $1.0221 \pm 0.003$ and no significant secondary nucleation was found in the vessel with the focused beam reflectance measurement (FBRM) probe monitoring the total counts during preparation.

At the start-up of a single-stage periodic flow MSMPR crystallization (Figure 1), the crystallizer was first cooled to $10{ }^{\circ} \mathrm{C}$, after which the feeding suspension was added at a flow rate of $52.7 \mathrm{~g} / \mathrm{min}$ by Pump 1 over a duration of $9.36 \mathrm{~min}$ to give a final operating volume of approximately $500 \mathrm{~mL}$. This was then followed by the switch-off of Pump 1 and a holding period of 10.64 min. Thereafter, a pumping period of simultaneous addition (Pump 1) of feeding suspension to and withdrawal (Pump 2) of product slurry from the MSMPR crystallizer was initiated and lasted for $9.36 \mathrm{~min}$, both at a fixed rate of $52.7 \mathrm{~g} / \mathrm{min}$. This was again followed by the switch-off of Pump $1 \& 2$ and another holding period of 10.64 min. Thereafter a repeated switch between pumping period and holding period continued until the MSMPR crystallizer reached a "steady" and repeatable oscillatory, viz., the "state of controlled operation”. The corresponding volume profile could be found in Figure 2(a). Incidentally, the holding period of time of 10.64 min was chosen empirically by observing the desupersaturation rate of glycine during the holding period, for other crystallization system, a longer holding time period would be expected for slower growing crystals, e.g. paracetamol.

In the case of a three-stage periodic flow MSMPR crystallization, the same start-up procedures were implemented, in sequence, to the first (MSMPR1), second (MSMPR2), and third (MSMPR3) crystallizer to fill up the vessels in order and finally reach a steady periodic flow operation. The operating volume of each MSMPR crystallizer was also approximately $500 \mathrm{~mL}$, but their temperatures were set to 17,14 , and $10{ }^{\circ} \mathrm{C}$, respectively, as shown in Figure 1. The idea here is to implement a step-wise cooling profile, with an aim to reduce the 
supersaturation level and also increase the total mean residence time and thus improve both the product mean crystal size and yield.

Importantly, it should be noted here that in the above implementation, only synchronous addition and withdrawal of materials are considered in the pumping period, defined here as the coupled periodic flow operation, which leads to a constant operating volume for each vessel after start-up. Hence, the time-averaged mean residence time of the single-stage periodic flow MSMPR crystallizer ( $\left.\mathrm{RT}_{\mathrm{PO}}\right)$ is the sum of the pumping period (9.36 min) and the holding period (10.64 min), i.e., 20 min. By adding a holding period, the mean residence time was significantly increased by 10.64 min when compared to a single-stage continuous flow MSMPR crystallizer operated at the same volume and with the same pumping flow rate. Accordingly, the $\mathrm{RT}_{\mathrm{PO}}$ for a three-stage periodic flow MSMPR crystallization is tripled to 60 min. However, due to the coupled operation of feeding and withdrawing, the corresponding residence time distributions of periodic flow MSMPR crystallizations would be as broad as that of continuous flow MSMPR crystallizer, which also attain the same mean residence time, i.e., by either lowering the flow rate (leads to particle setting and classification), or using a larger tank, which is twice the operating volume of the periodic flow process. In this regard, the periodic flow operation shows the benefits of reducing the equipment footprint and cost.

On the other hand, the periodic flow operation can also be operated in an asynchronous way, i.e., after the first filling of a single-stage MSMPR crystallizer, a holding period is applied to the pumps for a period of 10.64 min. Thereafter, the outlet pump from the crystallizer is switched on and half the volume is withdrawn, this is immediately followed by refilling with fresh feed as the inlet pump is switch on. The total time period for both pumping periods is $9.36 \mathrm{~min}$ (4.68 min each). Herein, it was described as the decoupled periodic flow operation. Schemes of the operating volume of the two periodic operation are illustrated in Figure 2. The benefits of the decoupled periodic operation are that it further 
extends the mean residence time and minimises the amount of feeding slurry to be directly washed out to the next stage, thus reducing the fine crystals at the final products.

Worth mentioning that a cascaded three-stage continuous flow MSMPR crystallization was also performed to serve as a benchmark to demonstrate the advantages of the periodic flow crystallization. Additionally, in all cases, the final slurry product withdrawn from each experiment was filtered and the final crystals were collected and dried at $40{ }^{\circ} \mathrm{C}$ for 24 hours. Besides, seed crystal samples were also taken and measured using laser diffraction in Malvern MasterSizer 2000 to obtain crystal size distributions. During all the crystallization experiments, a stirring speed of 400 rpm was found to be sufficient for particle suspension, and in situ PAT (Process Analytical Technology) tools were implemented to monitor the crystallization process, e.g. Raman spectroscopy was used to measure the GLY concentration, the focused beam reflectance measurement (FBRM) and particle vision microscopy (PVM) were used to observe the crystal counts, size, and shape collectively. An in-house developed crystallization process informatics system (CryPRINS) software tool was also applied for process monitoring and temperature control.

\section{Mathematical models}

\section{Dynamic model of residence time distribution}

The residence time distribution of the slurry in a crystallizer, providing major information on mean residence time and its corresponding standard deviation, is often studied for many innovative continuous crystallization techniques. ${ }^{27,}{ }^{28}$ Although a continuously operated stirred-tank crystallizer is usually assumed to obtain a perfect micro-mixing for liquid-solid phases in the vessel, ${ }^{19}$ the effect of macro-mixing due to feeding and withdrawing 
also plays a critical role in the crystallization operation and the final crystal attributes, i.e., crystal size distribution. Accordingly, a generic dynamic model was first developed for the residence time distribution of a stirred-tank crystallizer subject to different feeding and withdrawing operating patterns.

The system governing equations for the residence time distribution in a well-mixed stirred tank can be characterized as follows.

$$
\begin{gathered}
\frac{\partial(V W)}{\partial t}=-\frac{\partial(V W)}{\partial \theta}+\sum_{i=1}^{m} v_{i} F_{i}-\sum_{j=1}^{n} v_{j} E_{j} \\
\frac{d V}{d t}=\sum_{i=1}^{m} v_{i}-\sum_{j=1}^{n} v_{j}
\end{gathered}
$$

where $t$ is the real time, $\mathrm{s} ; V$ is the operating volume, $\mathrm{m}^{3} ; \theta$ is the age or residence time inside the vessel, $\mathrm{s} ; v_{i}$ is the feeding flowrate of $i$ th stream, $\mathrm{m}^{3} \mathrm{~s}^{-1} ; v_{j}$ is the withdrawing flowrate of $j$ th stream, $\mathrm{m}^{3} \mathrm{~s}^{-1} ; W(t, \theta)$ is the corresponding residence time distribution (RTD), $\mathrm{s}^{-1} ; F_{i}(t, \theta)$ is the RTD of $i$ th feeding stream, $\mathrm{s}^{-1} ; E_{j}(t, \theta)$ is the RTD of $j$ th exceeding stream, $\mathrm{s}^{-1}$, and is identical to the $W(t, \theta)$ for a well-mixed stirred tank. The corresponding initial and boundary conditions are listed as below.

$$
\begin{gathered}
W(0, \theta)=W_{0}(\theta) \\
V(0)=0 \\
W(t, 0)=0
\end{gathered}
$$

where $W_{0}(\theta)$ is the initial residence time distribution in the vessel, $\mathrm{s}^{-1}$. If the vessel starts from empty as in Eq. (4), $W_{0}(\theta)$ is a Dirac delta function (distribution) $\delta$, viz., $W_{0}$ is zero everywhere except at zero, with an integral of one over the entire residence time $\theta$. Besides, $F_{i}(t, \theta)$ is also a $\delta$ function if it is a fresh feed into the vessel. 
Owing to the simple convection term of $\partial \theta / \partial t=1$, the backward finite difference method (BFDM) was used here to discretise the above partial differential equation (PDE) (1) and solve the resulting ordinary differential equations (ODEs) together with Eq. (2) in MATLAB using “ode45”.

\section{Flowsheet models of periodic flow crystallization process}

Towards better process understanding and design of the novel periodic flow crystallization in MSMPR stages, rigorous population balance based mathematical modelling and flowsheet simulation were employed in this study by implementing the gCRYSTAL 4.0 (Process Systems Enterprise, UK) software package, which offers various particle sizechange mechanisms and kinetics for characterization of crystallization process, as well as convenient toolboxes for parameter estimation and process optimisation, etc.. The following briefly summarises the major steps in the implementation of gCRYSTAL for kinetic parameter estimation using batch cooling crystallization experiments and the simulation of periodic flow crystallizations.

First, system information and material properties of glycine and water, e.g., molecular weight, density, solubility, etc., which could be obtained elsewhere in the literature or chemical handbooks, ${ }^{22}$ were configured in the "global specification" module in gCRYSTAL. By adopting the module of "Crystallizer MSMPR" in the model library, configurations of the batch stirred-tank crystallizer were then set up according to the actual experimental conditions. In terms of the crystallization mechanisms and kinetics, instead of using theoretical, first-principles models for nucleation, crystal growth, and agglomeration, semiempirical power-law kinetic models were used here for chemical engineering purposes. For example, herein, a secondary nucleation model based upon the work of Ref. 29 was used to describe the nucleation effect due to attrition. And for crystal agglomeration effect, the $A_{50}$ 
parameter was introduced to represent the combined effect of material strength, point of contact between two crystals and vessel geometry. ${ }^{30}$ Details of the crystallization mechanisms and kinetic models selected in gCRYSTAL are summarised in Table 3. Further information about the model equations could be found in the help documentation of the gCRYSTAL software and the references therein.

After the model development for batch cooling crystallization, four batches of unseeded cooling crystallization experiments listed in Table 2 were imported into the gCRYSTAL folder of "Experiments>Performed", in which in situ real time measurements of GLY concentration, temperature, and crystal size distribution measured at the batch end were saved. "Perfect control" was chosen in the gCRYSTAL temperature controller so that the actual temperature profiles measured in the batch experiments could be imported as set points and were exactly tracked in the parameter estimation. Upon the successful inputs of the batch experimental data, a group of kinetic parameters listed in the Table $\mathbf{3}$ could be estimated using the "Parameter Estimations" tool in the software. Multiple tries of initial guesses were usually necessary to obtain a good agreement between model predictions and experimental measurements. In some cases, it is critical to re-examine the selected crystallization mechanisms by referring to the experimental observations, e.g., the effect of impeller stirring speed on nucleation by FBRM total counts, crystal agglomeration by PVM or microscopy images.

The modelling of periodic flow MSMPR crystallization was also implemented in gCRYSTAL, using multiple placements of transfer pumps and “Crystallizer MSMPR” stages in the flowsheet; a customised control module of "Intelligent Decision Support, IDS” was also developed in this study to logically switch on or off the pumps to realise the sequential start-up of multi-stage MSMPR crystallizers and to achieve the periodic flow operation. Both 
single- and three-stage MSMPR crystallization simulations were performed according to the actual experimental operating conditions as described in the last section. Their flowsheets are illustrated in Figure 3. Note that the same kinetic parameters estimated from the above batch cooling crystallization were incorporated here.

Additionally, unlike the simulation of batch unseeded cooling crystallizations, seeded feed suspensions were used in the periodic flow MSMPR crystallization which requires the specification of initial seed loading and crystal size distribution in gCRYSTAL. This could be done by importing the CSD measurements into the saved file of "Seed CSD.txt" in the "Miscellaneous Files" folder. It is worth mentioning that converting the discrete histogram Malvern CSD measurements of seed crystals into the volume-based density distribution is required in this saved text file. In addition, PI (Proportional and Integral) controllers were introduced in the gCRYSTAL temperature controller; their parameters of "Gain" and "Integral time" were fine-tuned to agree well with the dynamic response of the temperature measured in respective periodic flow experiment. This is because of the dynamic changes in temperature were possibly affected by the thermal capacity of cooling jacket of the crystallizer, e.g., liquid level, wall fouling, and so on.

\section{Results and discussion}

\section{Residence time distribution in periodic flow MSMPR crystallizer}

It would be of interest to demonstrate the residence time distribution of periodic flow operation in an MSMPR crystallizer and compare to that of a conventionally operated continuous flow operation when it is claimed that the periodic flow operation has the 
capability of extending the mean residence time without broadening the corresponding distribution too much.

The dynamic residence time distribution model has been applied to simulate the RTDs of an MSMPR crystallizer under continuous flow operation, coupled periodic flow operation, and decoupled periodic flow operation, with their experimental procedures described in section "Material and Experiments" and depicted in Figure 2. Their RTD results are shown in Figure 4. When reaches a state of controlled operation, it is found that the coupled periodic flow operation approximately doubled the mean residence time $\tau$, from 9.17 min under continuous flow operation to a time-averaged of $19.96 \mathrm{~min}$, but with a much more broaden residence time distributions, i.e., distribution standard deviation $\sigma$ changed from 9.50 min to 19.91 min. However, if one reduces the pumping flow rates for feeding and withdrawing of a continuous flow MSMPR crystallizer and thus doubles the mean residence time to $18.50 \mathrm{~min}$, the corresponding standard deviation would also rise up to $18.81 \mathrm{~min}$. On the other hand, if one compares from the coefficient of variation of their residence time distributions, c.v. $=\sigma / \tau$, the c.v. for continuous flow operations are 9.50/9.17 $=1.04$, or $18.81 / 18.50=1.02$; while the c.v. for coupled periodic flow operation is averaged at 19.91/19.96 $=1.00$. In this respect, the coupled periodic flow operation did extend the residence time but without broadening its distribution too much or out of expectation.

When it comes to the decoupled periodic flow operation, the time-averaged mean residence time was increased to 35.05 min with a standard deviation of about 28.15 min and a c.v. of around 0.8031. This was because of the decoupled pumping for feeding and withdrawing in such to minimise the possibly direct washing-out of the fresh feeding suspension. However, the productivity of a decoupled periodic operation would suffer a lot as the interruption to withdrawing was prolonged again and may merely show marginal advantages when compared to the batch operation in the aspect of productivity. Further, a 
very long time to a state of controlled operation was required during the start-up phase, e.g. looking at the RTD standard deviation in Figure 4. It should be pointed out that here only half of the slurry in the crystallizer was withdrawn and refilled in the decoupled periodic flow operation, however, if larger volume portion was involved, shorter residence time and narrower distribution would be observed with its limit approaching to a batch operation; while less volume would result in longer residence time and broader distribution. In practise, this should be designed and optimised with profound process understanding.

Hence, systematic study and optimisation of the effect of residence time distribution on crystal size distribution seem interesting and deserve more investigation effort. Future work will try to optimise the periodic flow operation for direct design and tailor of a residence time distribution in order to achieve on-spec critical product attributes.

\section{Kinetic parameter estimation from batch experiments}

The four batches of unseeded cooling crystallization in Table 2, spanning a range of initial concentrations with different cooling rates, were used to infer the major crystallization kinetics. Since no significant crystal agglomerates were observed by PVM or microscopic images for those unseeded batch experiments, as also shown in the microscopic insets of Figure 5; the agglomeration kinetics by "Mumtaz" in Table 3 was inactivated in the simulation and hence was not included in the parameter estimation at this stage.

The final results of parameter estimation are shown in Figure 5 and Table 4. Fouling of the Raman probe may occur due to the long operating time of more than 4 hours in BG-C3, potentially resulting in large uncertainties in the concentration measurement in the later course. Furthermore, in BG-C4, the concentration measurement in the later phase was obviously below the solubility limit. It should be pointed out that the solubility limit was calculated from the measured temperature profile in the crystallization experiment. Beside the 
PAT calibration errors at the low temperature, any uncertainties in the temperature control and measurement would result in this kind of deviation. For example, in BG-C4, at the time of about 0.75 hour, there was an unexpected increase in temperature during a cooling crystallization experiment. In BG-C1 and BG-C2 batch experiments, concentration measurement profiles were also slightly below the solubility limit at the tail part. While in BG-C4, nearly half of the concentration measurement trajectory was below the solubility limit. However, the gCRYSTAL simulations were only able to push the predicted concentration profile close to their respective solubility limit, hence the later phase of BG-C4 would lead to a large bias in the objective function for kinetic parameter estimation and may adversely affect the estimation result. Hence, only the first half of BG-C4 was used for parameter estimation. On the whole, reasonably good agreements are obtained between the measured and the predicted data for the solute concentration and crystal size distribution (measured at the end of BG-C1 \& C2). Uncertainties in the crystal size distribution may relate to the non-spherical and non-uniform crystal shape for the laser diffraction measurement and the use of single characteristic size for the one-dimensional population balance model in gCRYSTAL 4.0.

It is interesting to note the major peak in the final product crystal size distribution of BGC1 due to the mild primary nucleation when the GLY concentration hit the metastable zone boundary with moderate relative supersaturation at 0.25 ; while the minor peak in the small crystal size range was attributed to the secondary nucleation by crystal-impeller collision, which occurred under low supersaturation and the existence of large crystals, as observed in Figure 5 microscopic insect for BG-C1. To the contrary, the BG-C2 had triggered more intensive primary nucleation and faster crystal growth rate due to higher relative supersaturation at 0.55 (see the steep drop in concentration), which resulted into broad crystal size distribution. 


\section{Model validation by periodic flow MSMPR crystallizations}

Validation of the above crystallization mechanisms and kinetic parameters estimated from batch experiments were considered using periodic flow crystallization experiments conducted in either single- or cascaded three-stage MSMPR crystallizers, as described in the "Materials and Experiments” section. Two ground and sieved crystal seeds were used for each periodic flow crystallization experiments, viz., narrow fine seed crystals (mean size $\leq 75 \mu \mathrm{m}$ ) and bimodal coarse seed crystals (mean size $75 \sim 125 \mu \mathrm{m}$ ). For example, the two coupled periodic flow single-stage MSMPR crystallization experiments were: PSS1 (seeded with narrow fine crystals) and PSS2 (seeded with bimodal coarse crystals).

In an unseeded batch cooling crystallization, the nuclei were generated in majority by primary nucleation and were well dispersed in the slurry by stirring; in contrast, for the seeded MSMPR crystallizations in this study some were found with significant numbers of agglomerated crystals as observed using the PVM and microscopic images. This may be partly because of the ground and sieved seed crystals which were initially found to be agglomerated. The imperfect and rough surface of the seed crystals (reduced in size by grinding) may provide a low energy barrier for surface nucleation and bridging, leading to agglomerated crystals. For example, the initial seed and final crystals of PSS1 are illustrated in Figure 6. Nevertheless, more research efforts are needed in future studies.

Herein, a shortcut to take into account the agglomeration effect would be by considering the agglomeration kinetics of "Mumtaz kinetics" when agglomeration effect was observed in the MSMPR crystallization. In this regard, the agglomeration parameter $\left(\mathrm{A}_{50}\right)$ was fine-tuned 
in the simulation of PSS1 to fit the agglomerated CSD measurement while using the crystallization kinetic parameters listed in Table 4. A value of $60 \times 10^{-3} \mathrm{~N} / \mathrm{m}$ for $\mathrm{A}_{50}$ would result in good agreements both in GLY concentration and CSD, as shown in Figure 7 for PSS1.

Furthermore, another independent verification of all the kinetic parameters obtained so far was demonstrated by experiment PSS2 which was also affected by the agglomeration, as also shown in Figure 7. Even though larger sieved seed crystals with bimodal CSD were used in PSS2, the model predictions agreed relatively well with the experimental CSD measurements, which further confirms the predictive capability of the developed crystallization mechanism and kinetics.

Validations by coupled periodic flow cascaded three-stage MSMPR crystallization experiments, i.e., PCS1 (seeded with narrow fine crystals) and PCS2 (seeded with bimodal coarse crystals), are shown in Figures 8 to 10, where only solute concentration in the third crystallizer (MSMPR3) was measured, and three slurry samples taken at the end of the holding period for each crystallizer vessel were analysed by laser diffraction method.

It should be pointed out that, in a continuous flow MSMPR crystallization, it is not an issue when to take the slurry samples for off-line crystal size distribution measurement, so long as the system reaches its steady state. However, in a periodic flow operation, a state of controlled operation is achieved, viz., the system variables continuously varying in a limited range. Hence, in order to achieve better matches between predicted and measured data for crystal size distribution, the slurry samples should be taken with special care. As the two periods of holding and pumping are alternatively applied to the feeding and withdrawing pumps during operation; it is better, for cascaded crystallizer stages, to take the slurry samples when the crystallizer reaches the end point of the holding period, right before the 
pumping period, and in sequence of the last stage to the first stage. In such a way, the crystallizer is most likely to achieve the best mixing and also avoid the experimental perturbations in macro-mixing condition because of feeding, withdrawing, or sampling flows. Furthermore, taking the samples from the vessel bottom is faster than taking the samples from the discharge flow pump. The proposed sampling procedure has proved to be effective, with better matches between model prediction and experimental measurement. ${ }^{21}$

Despite uncertainties in the sampling and mixing conditions and the fact that crystallization kinetic parameters were previously estimated from batch cooling crystallization experiments without further tuning or re-estimating here, the proposed model predicted the solute concentration and crystal size distribution mostly well, except that the sample 3-3 in Figure 10 for PCS2 experiment. This may result from the too large needle shape crystals with varying aspect ratio, which will be further discussed in the following “Uncertainty Analyses and Summary” subsection.

In case of the model validation by decoupled periodic flow crystallization, a singlestage MSMPR crystallization was taken into account, i.e., DPSS (seeded with bimodal coarse crystals). The model predictions and their comparisons to the experimental measurements in solute concentration and crystal size distribution are illustrated in Figures 11 and 12, where good agreements are also obtained, except for the sample 1-3. As mentioned above, this may be due to the existence of very large needle shape crystals with varying aspect ratio. As also shown in Figure 4 for the residence time distribution of decoupled periodic flow crystallization, the process would take nearly 4 hours to reach a state of controlled operation. Interestingly, in Figure 12, the three samples took at 0.36, 2.00, 2.70 hrs showed the gradual increasing in the measured mean crystal size $(357.8 \mu \mathrm{m}, 601.8 \mu \mathrm{m}, 683.9 \mu \mathrm{m}$, respectively) and broadening in its crystal size distribution, consistent with the increasing values of mean residence time and standard deviation in Figure 4. 
Furthermore, it is also interesting to compare the periodic flow operation to the continuous flow operation using MSMPR crystallizers. For example, the comparison of final crystal size distributions by Malvern sizer or by model prediction in cascaded three-stage MSMPR crystallizers using coarse seed crystals are shown in Figure 13. Since the mean residence time had been doubled from $9.36 \times 3=28.08 \mathrm{~min}$ to $20.00 \times 3=60.00 \mathrm{~min}$ by periodic flow operation, as discussed in the "Material and Experiments" section, the experimentally measured volume-based mean particle size $D_{43 \text {, exp }}$ increased from $342.16 \mu \mathrm{m}$ to $696.76 \mu \mathrm{m}$, while the corresponding predicted value $D_{43}$, pred showed an increase from $184.38 \mu \mathrm{m}$ to $407.64 \mu \mathrm{m}$. Though the periodic flow operation has shown the benefits over the continuous flow operation, experimentally and in simulation, the large mismatch in CSD between the measurement and model prediction for the continuous flow crystallization is impressive. Beside the effect of needle shape crystals as mentioned for the mismatch for periodic flow operation, the crystallization kinetics estimated from the batch crystallization experiments in this study may not be appropriate for a continuous flow crystallization experiment, as the mixing conditions are so different and may have played a critical role in the kinetic parameter estimation. The applicability of this crystallization kinetics to the periodic flow operation may be due to the fact that this is a hybrid operation of batch and continuous operations.

\section{Uncertainty analyses and summary}

It has long been a concern with laser diffraction method for crystal size distribution measurement as usually the mismatches between the experimental measurements and model predictions are impressive (Ref. 31 and the references therein). Even nice agreements in the graphics for CSD measurements were mostly obtained, the volume-based mean particle size $D_{43}$ in Table 5, summarising all the experiments discussed in this study, shows significant 
differences between $D_{43}$, exp and $D_{43}$, pred for some of the cases. However, in order to objectively reveal the model accuracy, the relative errors were suggested and calculated as:

$$
\text { Rel.error }=\frac{D_{43, \text { pred }}-D_{43, \exp }}{D_{43, \exp }} \times 100 \%
$$

Note here that the experimental CSD measurements were provided in logarithmic scale and the same logarithmic scale was also used in the gCRYSTAL simulation, in which the data points are evenly placed along the logarithmic crystal size range. Therefore, during the parameter estimation, the predicted CSD curves are skewed due to the more measurement points in the small crystal size range than the median and large crystal size range. And it is the median size range where the desired $D_{43}$ is located. Minor mismatches in this range in the logarithmic scale will lead to large deviation in the linear crystal size scale. Therefore, due to the skewing effect, the suggested relative error in Eq. (6) may not provide an absolutely reasonable and fair metric for evaluating the model prediction accuracy in each crystallization experiment, provided the CSD measurement used in this work.

Nevertheless, it is also worth pointing out that the relative error shows an increasing trend in experiments PCS1, PCS2, and DPSS when the crystals grow into large size, which results into obvious mismatch in the mean crystal size $D_{43}$ or CSD in sample 3-3 in Figure 10 or in sample 1-3 in Figure 12. One of the possible reasons argued was that the GLY crystals shows a needle-shape morphology and with varying aspect ratios, as illustrated by the PVM images taken for PCS2 experiment in Figure 14. The adverse effect of varying aspect ratio in CSD measurements can be significant when the particles are large enough, which explains the increasing trend in relative prediction errors. In the future work, a multiple dimensional population balance model would be necessary to reduce the prediction error and control the crystal shape. ${ }^{32,33,34}$ Correspondingly, in-situ PVM images providing the crystal shape and size measurements are also highly demanded. ${ }^{35}$ 
To sum up accordingly, the estimated crystallization mechanism and kinetics from batch cooling crystallization experiments have been shown with good predictive capability either in coupled periodic flow crystallization in single- / three-stage MSMPR crystallizers or in decoupled periodic flow crystallization in a single-stage crystallizer, which proves its further implementation in process design, optimisation, and control. ${ }^{36,37}$

\section{Conclusions}

The novel periodic flow operation was demonstrated from the perspective of residence time distribution and compared to that of the conventional continuous flow operation. The merit of extended residence time without over broadening its distribution by periodic flow operation has made it attractive for crystallization system when the mean residence time is an important design variable. Mathematical modelling and simulation of periodic flow crystallization processes using single and multiple MSMPR stages were summarised, wherein crystallization mechanisms and kinetic parameters for glycine and water system were estimated from unseeded batch cooling crystallization experiments and verified with periodic flow single-/three-stage MSMPR crystallizations. Reasonably good agreements were obtained between the experimental measurements and model predictions with model uncertainties analysed and future work suggested. Moreover, advantages of the periodic flow crystallization were proved through experiments and simulations. 


\section{Acknowledgement}

This work was performed within the UK EPSRC funded project (EP/K014250/1) 'Intelligent Decision Support and Control Technologies for Continuous Manufacturing and Crystallization of Pharmaceuticals and Fine Chemicals’ (ICT-CMAC). The authors would like to acknowledge financial support from European Research Council under the European Union's Seventh Framework Programme (FP7/2007-2013)/ERC grant agreement no. [280106-CrySys], AstraZeneca and GlaxoSmithKline. The authors are also grateful for useful discussions with industrial partners from AstraZeneca, GlaxoSmithKline, Mettler-Toledo, Perceptive Engineering and Process Systems Enterprise. 


\section{References}

1. Alvarez AJ, Myerson AL. Continuous plug flow crystallization of pharmaceutical compounds. Crystal Growth \& Design. 2010; 10: 2219-2228.

2. Kessel M. The problems with today's pharmaceutical business - an outsider's view. Nature Biotechnology. 2011; 29: 27-33.

3. Leuenberger $\mathrm{H}$. New trends in the production of pharmaceutical granules: batch versus continuous processing. European Journal of Pharmaceutics and Biopharmaceutics. 2001;52: 289-296.

4. Buchholz S. Future manufacturing approaches in the chemical and pharmaceutical industry. Chemical Engineering and Processing. 2010; 49: 993-995.

5. Vetter T, Burcham CL, Doherty MF. Regions of attainable particle sizes in continuous and batch crystallization processes. Chemical Engineering Science. 2014;106:167-180.

6. Eder RJP, Radl S, Schmitt E, Innerhofer S, Maier M, Gruber-Woelfler H, Khinast JG. Continuously seeded, continuously operated tubular crystallizer for the production of active pharmaceutical ingredients. Crystal Growth \& Design. 2010; 10: 2247-2257.

7. Wong SY, Tatusko AP, Trout BL, Myerson AL. Development of continuous crystallization processes using a single-stage mixed-suspension, mixed-product removal crystallizer with recycle. Crystal Growth \& Design. 2012; 12: 5701-5707.

8. Lawton S, Steele G, Shering P, Zhao L, Laird I, Ni XW. Continuous crystallization of pharmaceuticals using a continuous oscillatory baffled crystallizer. Organic Process Research \& Development. 2009; 13: 1357-1363.

9. Jiang M, Zhu Z, Jimenez E, Papageorgiou CD, Waetzig J, Hardy A, Langston M, Braatz RD. Continuous-flow tubular crystallization in a slugs spontaneously induced by hydrodynamics. Crystal Growth \& Design. 2014; 14: 851-860. 
10. Ridder BJ, Majumder A, Nagy ZK. Population balance model based multi-objective optimization of a multi-segment multi-addition (MSMA) continuous plug flow antisolvent crystallizer. Industrial \& Engineering Chemistry Research. 2014; 53: 43874397.

11. Su Q, Benyahia B, Nagy ZK, Rielly CD. Mathematical modelling, design, and optimization of a multi-segment multi-addition plug-flow crystallizer for anti-solvent crystallizations. Organic Process Research \& Development. 2015; 19: 1859-1870.

12. Majumder A, Nagy ZK. Fines removal in a continuous plug flow crystallizer by optimal spatial temperature profiles with controlled dissolution. AIChE Journal. 2013; 59: 4582-4594.

13. Alvarez AJ, Singh A, Myerson AS. Crystallization of cyclosporine in a multistage continuous MSMPR crystallizer. Crystal Growth \& Design. 2011; 11: 4392-4400.

14. Zhang H, Quon J, Alvarez AJ, Evans J, Myerson AS, Trout B. Development of continuous anti-solvent/cooling crystallization process using cascaded mixed suspension, mixed product removal crystallizers. Organic Process Research \& Development. 2012; 16; 915-924.

15. Su Q, Nagy ZK, Rielly CD. Pharmaceutical crystallisation processes from batch to continuous operation using MSMPR stages: modelling, design, and control. Chemical Engineering and Processing: Process Intensification. 2015; 89: 41-53.

16. Kwon JS, Nayhouse M, Orkoulas G, Christofides PD. Enhancing the crystal production rate and reducing polydispersity in continuous protein crystallization. Industrial \& Engineering Chemistry Research. 2014a; 53: 15538-15548.

17. Griffin DW, Mellichamp DA, Doherty MF. Reducing the mean size of API crystals by continuous manufacturing with product classification and recycle. Chemical Engineering Science. 2010; 65: 5770-5780. 
18. Kwon JS, Nayhouse M, Orkoulas G, Christofides PD. Crystal shape and size control using a plug flow crystallization configuration. Chemical Engineering Science. 2014b; 119: 30-39.

19. Scully J, Frawley P. Computational fluid dynamics analysis of the suspension of nonspherical particles in a stirred tank. Industrial \& Engineering Chemistry Research. 2011; 50: 2331-2342.

20. Powell KA, Saleemi AN, Rielly CD, Nagy ZK. Periodic steady-state flow crystallization of a pharmaceutical drug using MSMPR operation. Chemical Engineering and Processing: Process Intensification. 2015; 97: 195-212

21. Powell KA, Su Q, Rielly CD, Nagy ZK. Experimental and mathematical evaluation of a novel periodic flow crystallization process using single/three-stage MSMPR crystallizers: Part I - Example of a fast growing active pharmaceutical ingredient. Submitting, 2015.

22. Mullin JW. Crystallisation, 2nd ed., Butterworths, London, 1972.

23. Mitchell NA, Frawley PJ. Nucleation kinetics of paracetamol-ethanol solutions from metastable zone widths. Journal of Crystal Growth. 2010; 312(19): 2740-2746.

24. Mitchell NA, Frawley PJ, Ó'Ciardhá CT. Nucleation kinetics of paracetamol-ethanol solutions from induction time experiments using Lasentec FBRM®. Journal of Crystal Growth. 2011a; 321:91-99.

25. Nagy ZK, Fujiwara M, Woo XY, Braatz RD. Determination of the kinetic parameters for the crystallization of paracetamol from water using metastable zone width experiments. Industry \& Engineering Chemistry Research. 2008; 47(4):1245-1252.

26. Mitchell NA, Ó'Ciardhá CT, Frawley PJ. Estimation of the growth kinetics for the cooling crystallisation of paracetamol and ethanol solutions. Journal of Crystal Growth. 2011b; 328:39-49. 
27. Reis N, Vicente AA, Teixeira JA, Mackley MR. Residence times and mixing of a novel continuous oscillatory flow screening reactor. Chemical Engineering Science. 2004; 59: 4967-4974.

28. Reis N, Vicente AA, Teixeira JA. Liquid backmixing in oscillatory flow through a periodically constricted meso-tube. Chemical Engineering and Processing: Process Intensification. 2010; 49: 793-803.

29. Evans TW, Sarofim AF, Margolis G. Models of secondary nucleation attributable to crystal-crystallizer and crystal-crystal collisions. AIChE Journal. 1974; 20(5):959.

30. Mumtaz HS, Hounslow MJ, Seaton NA, Paterson WR. Orthokinetic aggregation during precipitation: a computational model for calcium oxalate monohydrate. Trans. IChemE. 1997; 75(A): 15.

31. Su Q, Chiu M, Braatz RD. Modeling and Bayesian parameter estimation for semibatch pH-shift reactive crystallisation of L-glutamic acid. AIChE Journal. 2014; 60: 28282838.

32. Majumder A, Nagy ZK. Prediction and control of crystal shape distribution in the presence of crystal growth modifiers. Chemical Engineering Science. 2013b; 101: 593602.

33. Kwon JS, Nayhouse M, Orkoulas G, Christofides PD. Crystal shape and size control using a plug flow crystallization configuration. Chemical Engineering Science. 2014; 119:30-39.

34. Jiang M, Zhu X, Molaro MC, Rasche ML, Zhang H, Chadwich K, Raimondo DM, Kim WKK, Zhou L, Zhu Z, Wong MH, O'Grady D, Hebrault D, Tedesco J, Braatz RD. Modification of crystal shape through deep temperature cycling. Industry \& Engineering Chemistry Research. 2014; 53: 5325-5336. 
35. Zhou Y, Doan XT, Srinivasan R. On-line monitoring of particle shape and size distribution in crystallization processes through image analysis. In: 17th European Symposium on Computer Aided Process Engineering-ESCAPE17.

36. Yang Y, Nagy ZK. Advanced control approaches for combined cooling/antisolvent crystallization in continuous mixed suspension mixed product removal cascade crystallizers. Chemical Engineering Science. 2015; 127:362-373.

37. Yang Y, Nagy Z.K. Combined cooling and antisolvent crystallization (CCAC) in continuous MSMPR cascade: steady state and startup optimization. Industries \& Engineering Chemistry Research. 2015;54: 5673-5682. 


\section{Figure captions}

Figure 1 Block diagrams of the periodic flow MSMPR crystallization experiments: singlestage crystallization (top); cascaded three-stage crystallizations.

Figure 2 Schemes of the periodic flow MSMPR crystallization experiments: (a) coupled periodic operation; (b) decoupled periodic operation.

Figure 3 Flowsheet of the periodic flow crystallization experiments: single-stage MSMPR crystallizer (top); cascaded three-stage MSMPR crystallizers.

Figure 4 Residence time distributions of an MSMPR crystallizer under continuous flow operation (top three), coupled periodic flow operation (centre three), and decoupled periodic flow operation (bottom three) (The bold solid lines on the right half indicate when the withdrawing pumps are switched on).

Figure 5 Results of kinetic parameter estimation using unseeded batch cooling crystallizations.

Figure 6 Agglomerated initial fine seed crystals and final crystals from PSS1 experiment observed in microscopy.

Figure 7 Comparisons of predicted and measured data for period flow single-stage MSMPR crystallizations (CSD measurements were taken at the start of pumping period after reaching a state of controlled operation).

Figure 8 Comparisons of predicted and measured data for solute concentration in the third crystallizer (MSMPR 3) of the periodic flow cascaded three-stage MSMPR crystallizations. 
Figure 9 Comparisons of crystal size distributions between predictions and measurements in the three crystallizers for PCS1 experiment (solid line: predicted; dash line: measured).

Figure 10 Comparisons of crystal size distributions between predictions and measurements in the three crystallizers for PCS2 experiment (solid line: predicted; dash line: measured).

Figure 11 Comparisons of concentration between predictions and measurements for DPSS experiment.

Figure 12 Comparisons of crystal size distributions between predictions and measurements for DPSS experiment (solid line: predicted; dash line: measured).

Figure 13 Comparisons of crystal size distribution measurements between continuous flow operation and periodic flow operation with cascaded three-stage MSMPR crystallizers.

Figure 14 PVM images taken for the last stage crystallizer MSMPR3 in PPS2 experiment. 


\section{Table lists}

Table 1 Comparison of batch, continuous, and periodic operations of stirred tank crystallizer.

Table 2 Summary of four batches of unseeded cooling crystallization.

Table 3 Summary of the crystallization mechanisms and kinetic models.

Table 4 Results of kinetics parameter estimation.

Table 5 Comparisons of volume-based mean particle size $D_{43}$. 
Table 1 Comparison of batch, continuous, and periodic operations of stirred tank crystallizer.

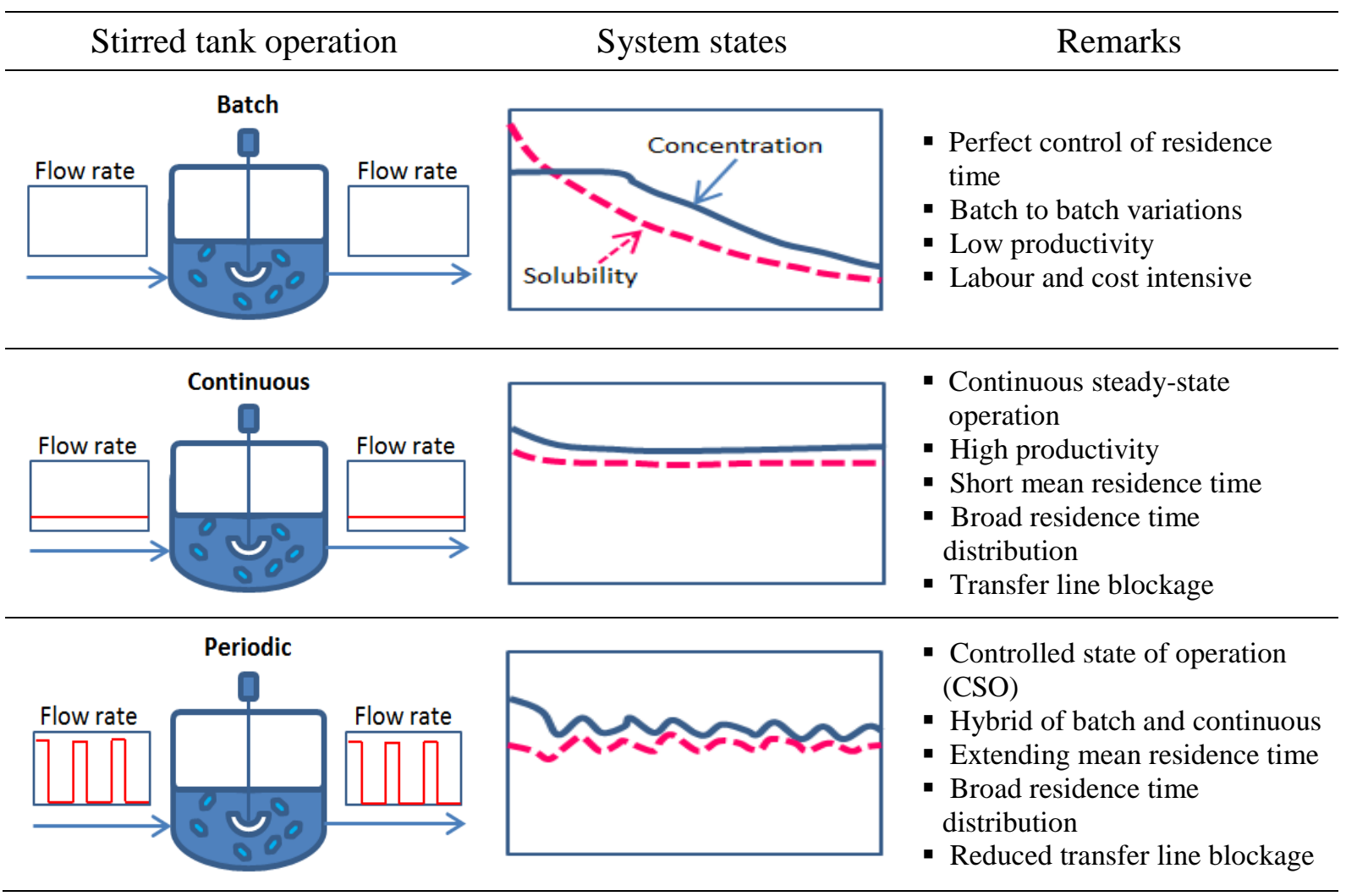

Table 2 Summary of four batches of unseeded cooling crystallization.

\begin{tabular}{ccccccr}
\hline $\begin{array}{c}\text { Exp. } \\
\text { No. }\end{array}$ & $\begin{array}{c}\text { Initial Conc. } \\
\mathrm{C}_{0}(\mathrm{~g} / \mathrm{g})\end{array}$ & $\begin{array}{c}\text { Sat. Temp. } \\
\mathrm{T}_{\text {sat }}\left({ }^{\circ} \mathrm{C}\right)\end{array}$ & $\begin{array}{c}\text { Cooling rate } \\
\left({ }^{\circ} \mathrm{C} / \mathrm{min}\right)\end{array}$ & $\begin{array}{c}\text { Initial } \\
\text { Temp }\left({ }^{\circ} \mathrm{C}\right)\end{array}$ & $\begin{array}{c}\text { Final } \\
\text { Temp. }\left({ }^{\circ} \mathrm{C}\right)\end{array}$ & $\begin{array}{c}\text { Batch Time } \\
(\mathrm{min})\end{array}$ \\
\hline BG-C1 & 0.4120 & 55.0 & 0.70 & 70.0 & 6.0 & 107.0 \\
BG-C2 & 0.3248 & 40.0 & 0.65 & 50.0 & 6.0 & 90.0 \\
BG-C3 & 0.3246 & 40.0 & 0.10 & 50.0 & 25.0 & 250.0 \\
BG-C4 & 0.2801 & 30.0 & 0.55 & 40.0 & 6.0 & 93.0 \\
\hline
\end{tabular}


Table 3 Summary of the crystallization mechanisms and kinetic models

\begin{tabular}{|c|c|c|c|}
\hline Mechanism & Kinetics & Options & Parameters \\
\hline $\begin{array}{c}\text { Primary } \\
\text { nucleation }\end{array}$ & $\begin{array}{l}\text { Customized power law kinetics } \\
J_{\text {prim }}=k_{n} \sigma^{n_{1}} \exp \left(\frac{-E_{A, n}}{R T}\right) C^{n_{2}}\end{array}$ & $\begin{array}{c}\text { Relative } \\
\text { supersaturation } \\
\sigma=\left(C-C_{\text {sat }}\right) / C_{\text {sat }}\end{array}$ & $\begin{array}{l}\text { - Rate constant } k_{n} \\
\text { - Supersaturation order } n_{1} \\
\text { - Activation energy } E_{A, n} \\
\text { - Order with respect to solute } \\
\text { concentration } n_{2} \\
\end{array}$ \\
\hline $\begin{array}{l}\text { Secondary } \\
\text { nucleation }\end{array}$ & $\begin{array}{l}\quad \text { Evans kinetics } \\
J_{\text {sec } \__{-} i} \\
=\mathrm{k}_{n_{-} c i} \sigma^{n_{c i}} \frac{N_{Q}}{N_{P}} k_{v} \rho_{c} \varepsilon \int_{L_{\text {min } \_c i}}^{\infty} n L^{3} d L\end{array}$ & $\begin{array}{c}\text { Collision type: } \\
\text { Crystal-Impeller (CI) }\end{array}$ & $\begin{array}{l}\text { - Rate constant } k_{n_{-} c i} \\
\text { - Impeller flow number } N_{Q} \\
\text { - Impeller power number } N_{P} \\
\text { - Volume shape factor } k_{v} \\
\text { - Crystal density } \rho_{c} \\
\text { - Energy dissipation energy } \varepsilon \\
\text { - Size above which crystals } \\
\text { undergo attrition } L_{\text {min_ci }} \\
\text { - Crystal number density } n \\
\text { - Order with respect to } \\
\text { supersaturation } n_{c i}\end{array}$ \\
\hline Crystal growth & $\begin{array}{c}\text { Power law kinetics } \\
G=k_{g} \exp \left(\frac{-E_{A, g}}{R T}\right) \sigma^{g}\end{array}$ & $\begin{array}{c}\text { Relative } \\
\text { supersaturation }\end{array}$ & $\begin{array}{l}\text { - Growth rate constant } k_{g} \\
\text { - Order with respect to } \\
\text { supersaturation } g \\
\text { - Activation energy } E_{A, g} \\
\end{array}$ \\
\hline Agglomeration & $\begin{array}{c}\text { Mumtaz kinetics } \\
\beta_{\text {agg }}=\psi\left(A_{50}\right) \beta_{\text {coll }}\end{array}$ & - & $\begin{array}{l}\text { - Agglomeration efficiency } \psi \\
\text { - Lumped agglomeration } \\
\text { parameter }\left(\mathrm{A}_{50}\right) \\
\text { - Collision rate constant } \beta_{\text {coll }} \\
\end{array}$ \\
\hline
\end{tabular}

Table 4 Results of kinetics parameter estimation

\begin{tabular}{|c|c|c|c|}
\hline Kinetics & Parameter & Estimate & Unit \\
\hline \multirow{4}{*}{$\begin{array}{l}\text { Primary nucleation: } \\
\text { Customized power law } \\
\text { kinetics }\end{array}$} & Rate constant $k_{n}$ & $1673.83 \pm 22.82$ & LOG(\#/s) \\
\hline & Supersaturation order $n_{1}$ & $4.23 \pm 0.013$ & - \\
\hline & Activation energy $E_{A, n}$ & $1284.64 \pm 147.4$ & $\mathrm{~J} / \mathrm{mol}$ \\
\hline & $\begin{array}{l}\text { Order with respect to solute } \\
\text { concentration } n_{2}\end{array}$ & $3.41 \pm 0.013$ & - \\
\hline \multirow{3}{*}{$\begin{array}{l}\text { Secondary nucleation: } \\
\text { Evans kinetics }\end{array}$} & Rate constant $k_{n, c i}$ & $16.40 \pm 0.009$ & $\mathrm{LOG}(\# / \mathrm{s})$ \\
\hline & $\begin{array}{l}\text { Size above which crystals } \\
\text { undergo attrition } L_{m i n, c i}\end{array}$ & 798.35 & $\mu \mathrm{m}$ \\
\hline & $\begin{array}{l}\text { Order with respect to } \\
\text { supersaturation } n_{c i}\end{array}$ & $1.00 *$ & - \\
\hline \multirow{3}{*}{$\begin{array}{l}\text { Crystal growth: } \\
\text { Power law kinetics }\end{array}$} & Growth rate constant $k_{g}$ & $1.49 \times 10^{-5} \pm 3.52 \times 10^{-8}$ & $\mathrm{~m} / \mathrm{s}$ \\
\hline & $\begin{array}{l}\text { Order with respect to } \\
\text { supersaturation } g\end{array}$ & $1.71 \pm 0.0010$ & - \\
\hline & Activation energy $E_{A, g}$ & $0.00 *$ & $\mathrm{~J} / \mathrm{mol}$ \\
\hline $\begin{array}{l}\text { Agglomeration: } \\
\text { Mumtaz kinetics }\end{array}$ & $\begin{array}{l}\text { Agglomeration parameter } \\
\left(\mathrm{A}_{50}\right)\end{array}$ & $60.00 \times 10^{-3}$ & $\mathrm{~N} / \mathrm{m}$ \\
\hline
\end{tabular}

* The final estimates hit the lower bound. 
Table 5 Comparisons of volume-based mean particle size $D_{43}$

\begin{tabular}{|c|c|c|c|c|}
\hline & Experiments & $D_{43, \exp }(\mu \mathrm{m})$ & $D_{43, \text { pred }}(\mu \mathrm{m})$ & Rel. error \\
\hline \multirow{4}{*}{ Batch } & Sample at BG-C1 end & 498.99 & 454.62 & $-1.50 \%$ \\
\hline & Sample at BG-C2 end & 447.86 & 360.00 & $-3.58 \%$ \\
\hline & Sample at BG-C end & - & 321.99 & - \\
\hline & Sample at BG-C4 end & - & 319.27 & - \\
\hline PSS1 & Controlled state average & 167.48 & 183.21 & $1.75 \%$ \\
\hline PSS2 & Controlled state average & 287.64 & 216.60 & $-5.01 \%$ \\
\hline \multirow{3}{*}{ PCS1 } & Sample 3-1 & 238.10 & 226.67 & $-0.90 \%$ \\
\hline & Sample 3-2 & 278.70 & 264.55 & $-0.93 \%$ \\
\hline & Sample 3-3 & 348.30 & 267.87 & $-4.49 \%$ \\
\hline \multirow{3}{*}{ PCS2 } & Sample 3-1 & 364.41 & 362.34 & $-0.10 \%$ \\
\hline & Sample 3-2 & 519.54 & 409.39 & $-3.81 \%$ \\
\hline & Sample 3-3 & 696.76 & 407.64 & $-8.19 \%$ \\
\hline \multirow{3}{*}{ DPSS } & Sample 1-1 & 357.83 & 362.89 & $0.24 \%$ \\
\hline & Sample 1-2 & 601.78 & 431.65 & $-5.18 \%$ \\
\hline & Sample 1-3 & 683.88 & 418.52 & $-7.52 \%$ \\
\hline CCS & Steady-state & 342.16 & 184.38 & $-10.60 \%$ \\
\hline
\end{tabular}



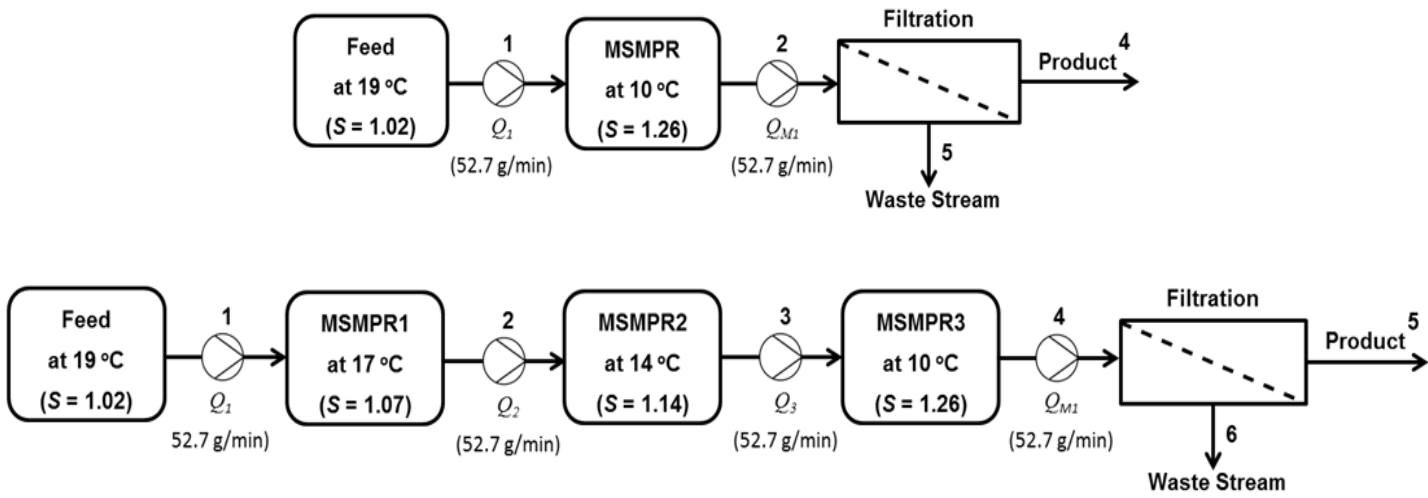

Figure 1 Block diagrams of the periodic flow MSMPR crystallization experiments: singlestage crystallization (top); cascaded three-stage crystallizations.

(a) Coupled Periodic Flow

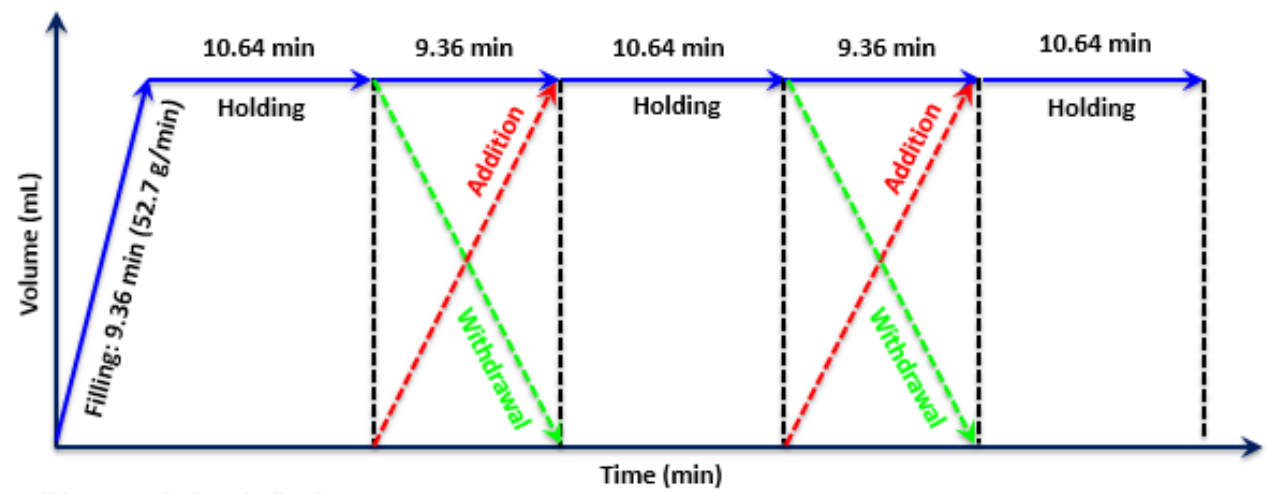

(b) Decoupled Periodic Flow

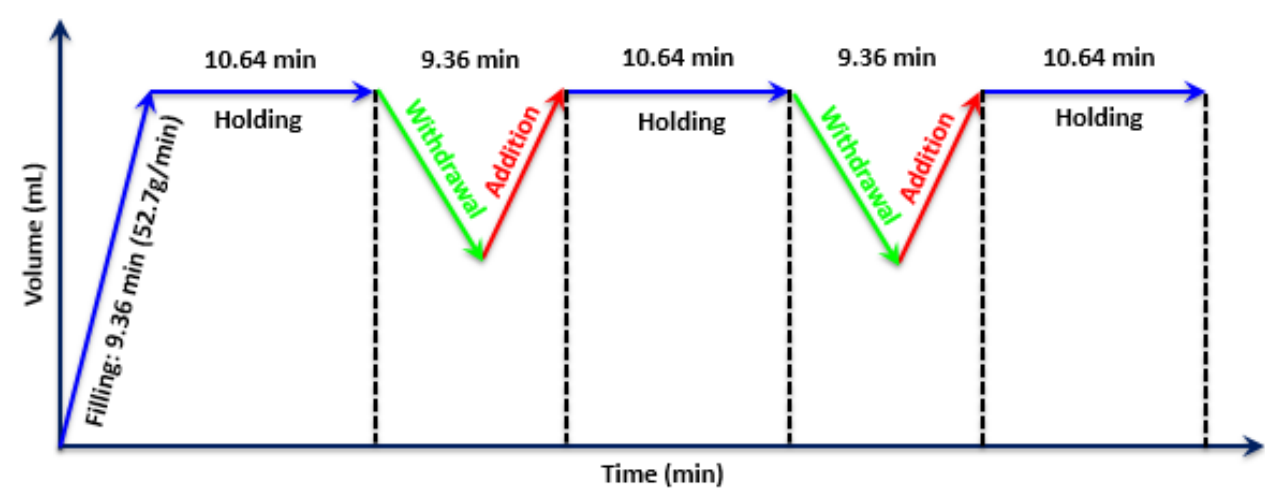

Figure 2 Schemes of the periodic flow MSMPR crystallization experiments: (a) coupled periodic operation; (b) decoupled periodic operation. 

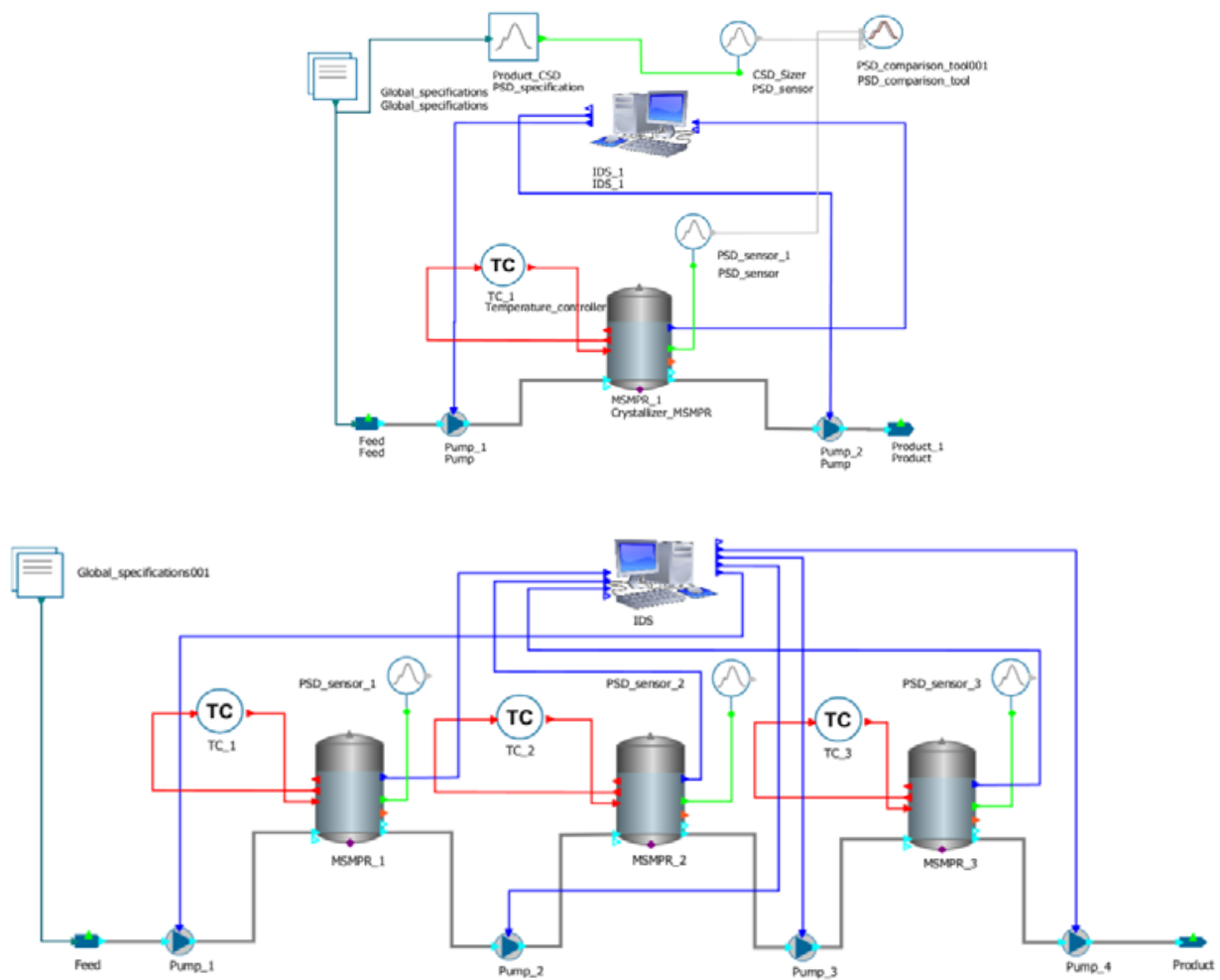

Figure 3 Flowsheet of the periodic flow crystallization experiments: single-stage MSMPR crystallizer (top); cascaded three-stage MSMPR crystallizers. 

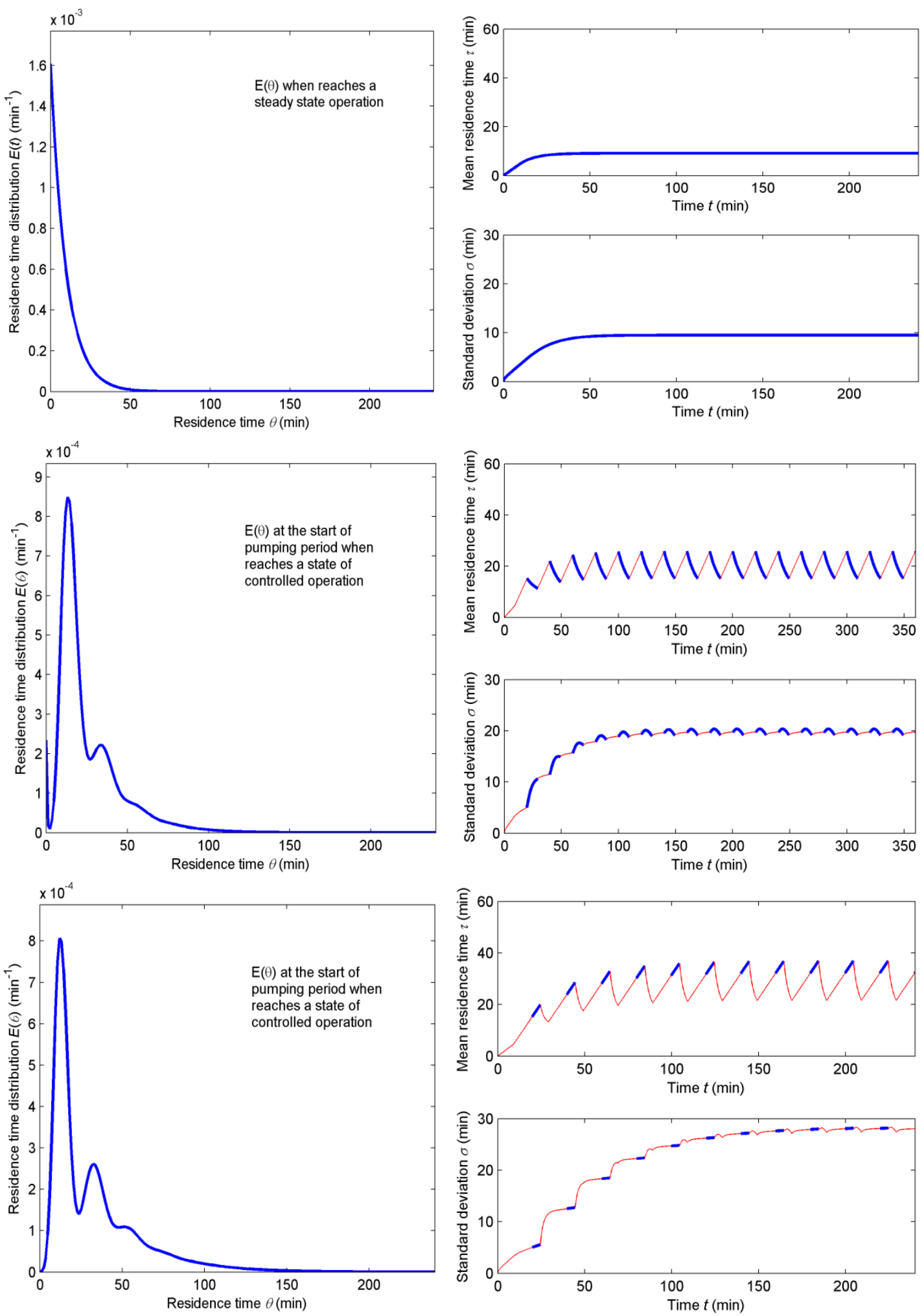

Figure 4 Residence time distributions of an MSMPR crystallizer under continuous flow operation (top three), coupled periodic flow operation (centre three), and decoupled periodic flow operation (bottom three) (The bold solid lines on the right half indicate when the withdrawing pumps are switched on). 

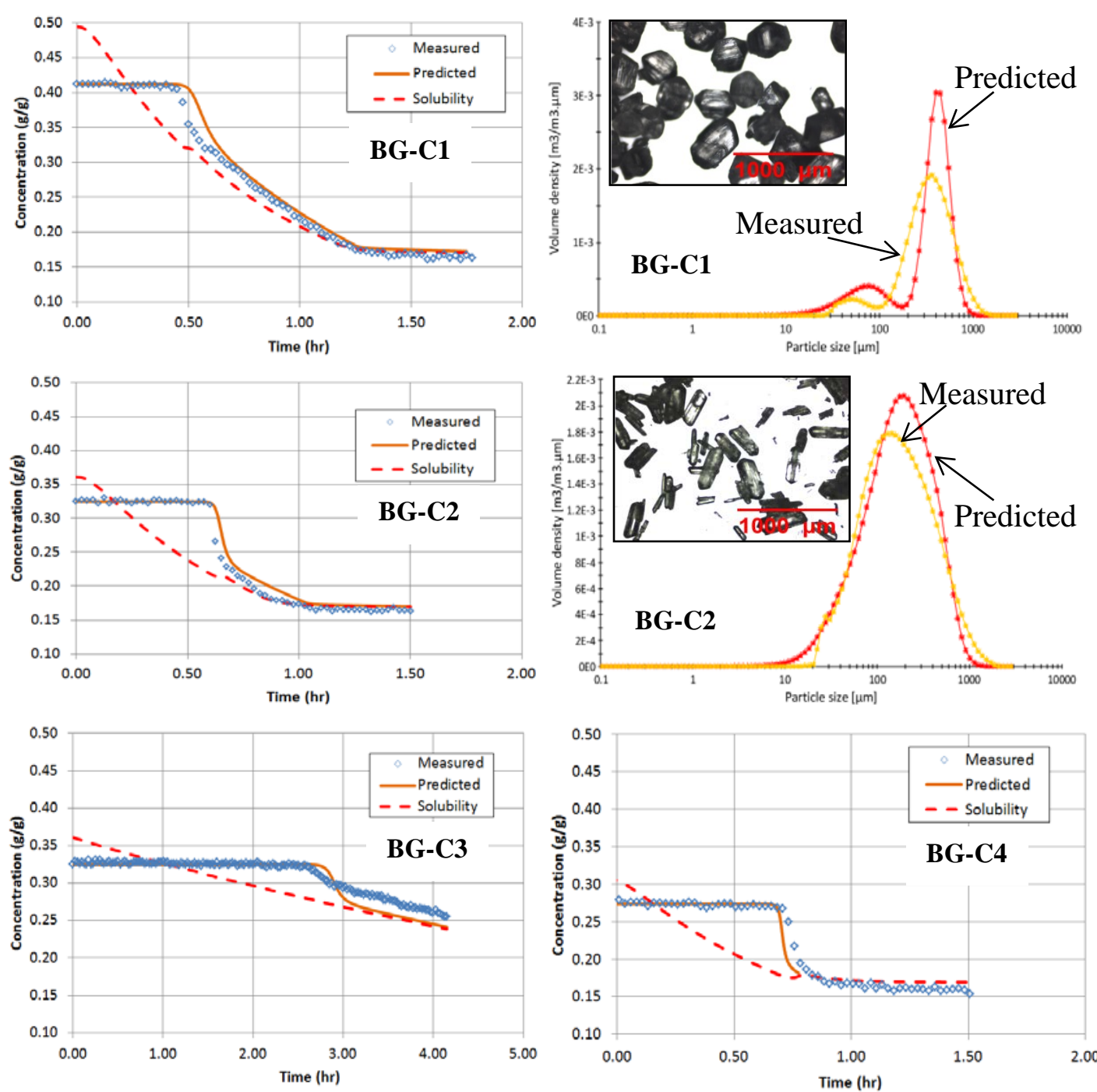

Figure 5 Results of kinetic parameter estimation using unseeded batch cooling crystallizations. 

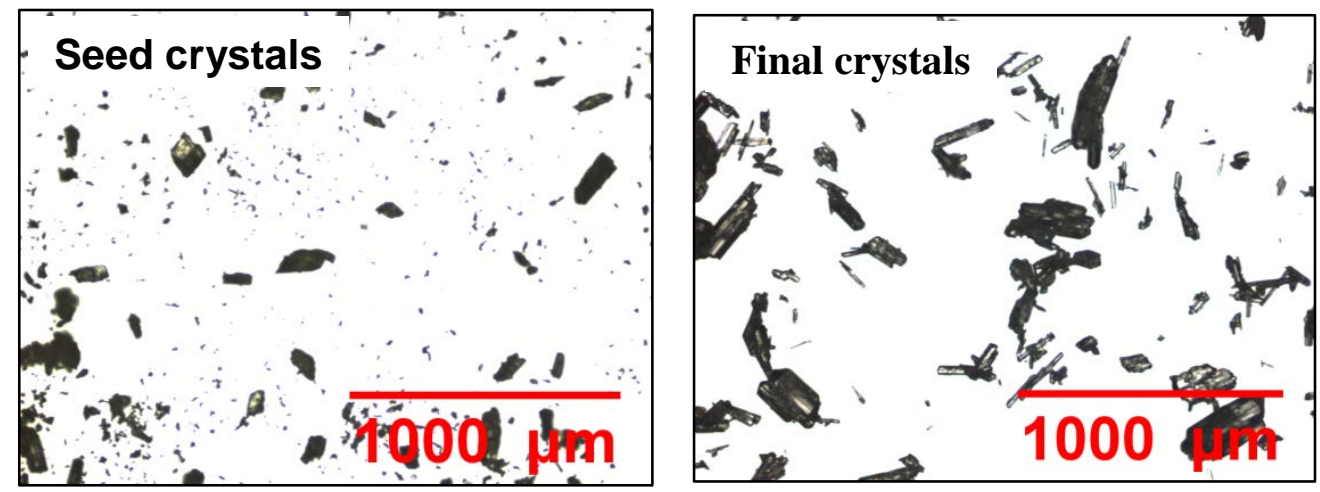

Figure 6 Agglomerated initial fine seed crystals and final crystals from PSS1 experiment observed in microscopy.
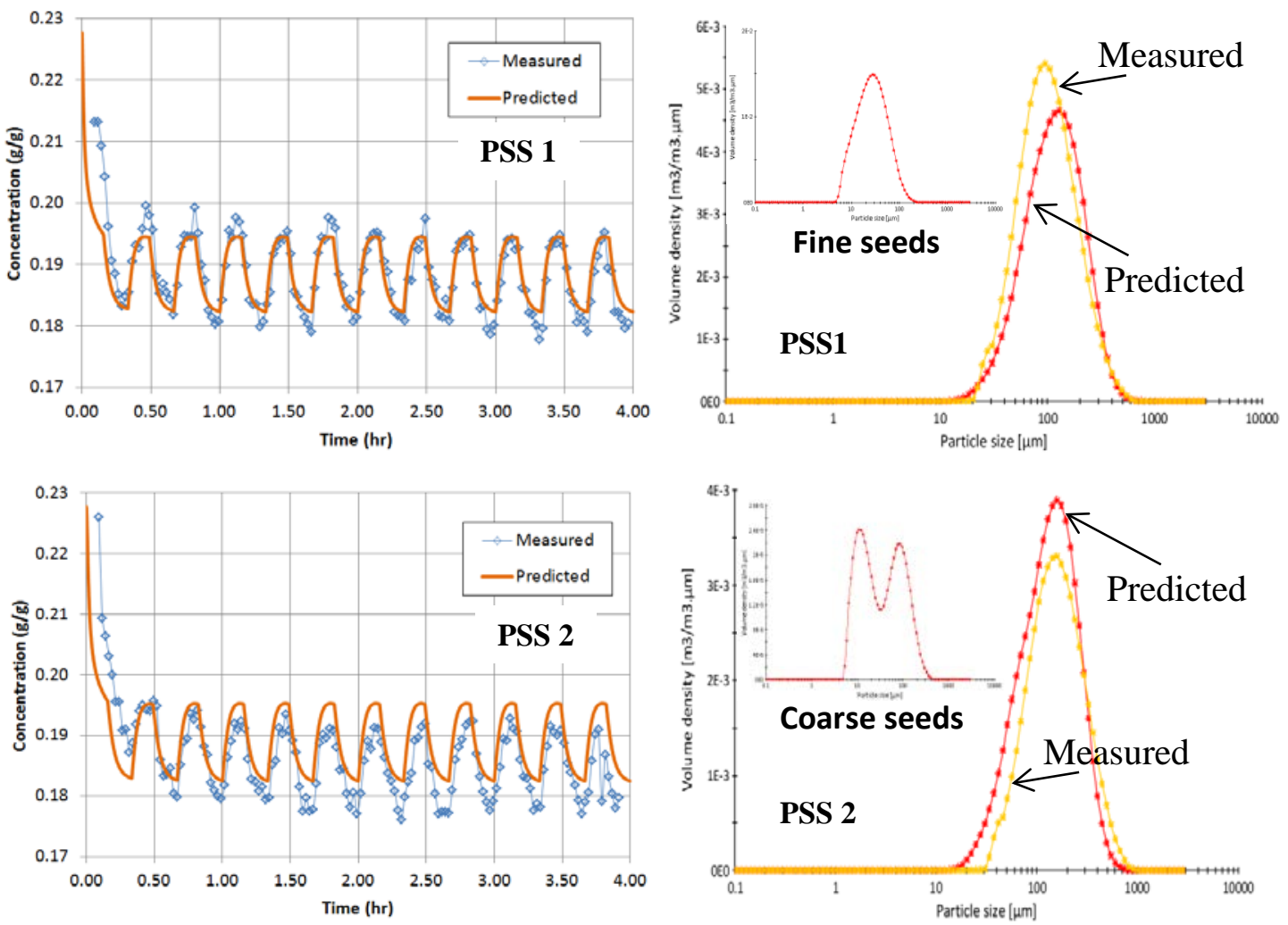

Figure 7 Comparisons of predicted and measured data for period flow single-stage MSMPR crystallizations (CSD measurements were taken at the start of pumping period after reaching a state of controlled operation). 

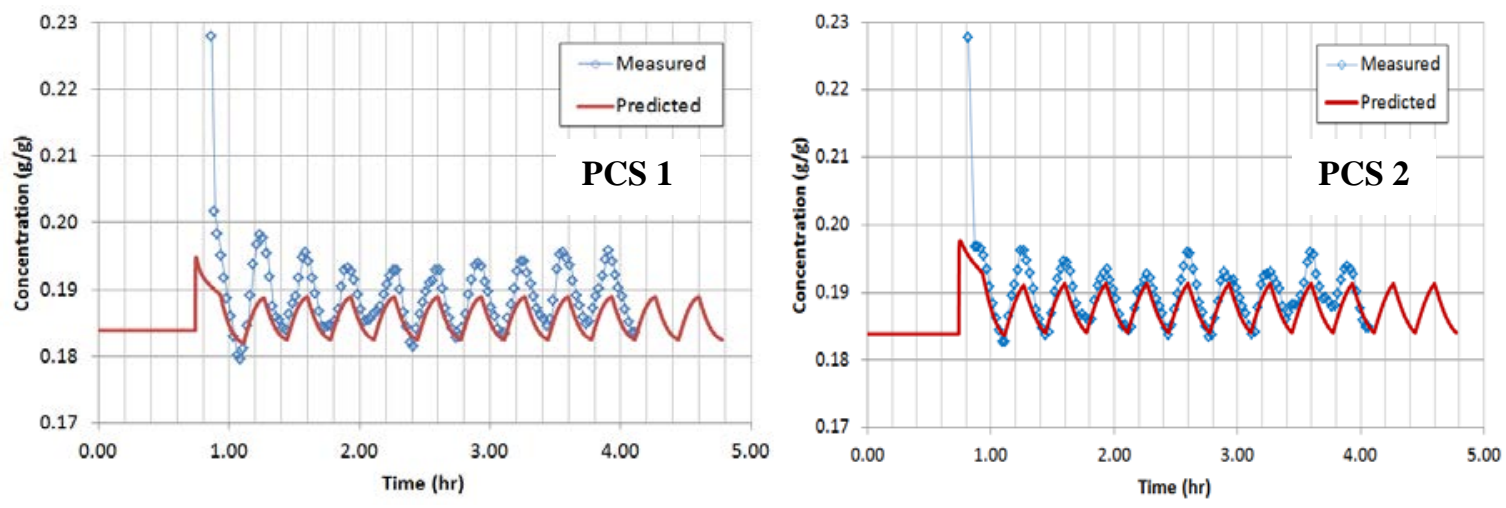

Figure 8 Comparisons of predicted and measured data for solute concentration in the third crystallizer (MSMPR 3) of the periodic flow cascaded three-stage MSMPR crystallizations.
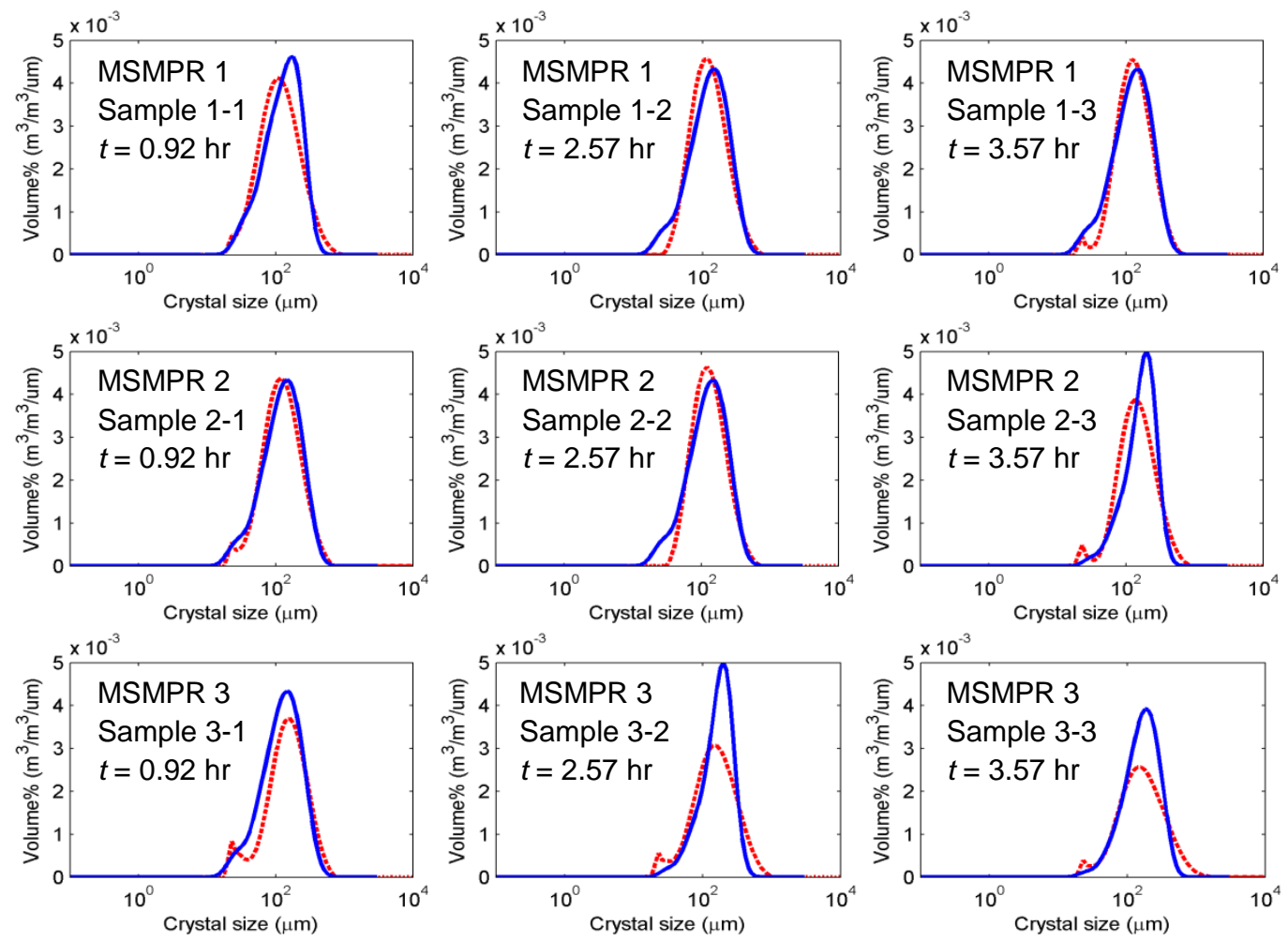

Figure 9 Comparisons of crystal size distributions between predictions and measurements in the three crystallizers for PCS1 experiment (solid line: predicted; dash line: measured). 

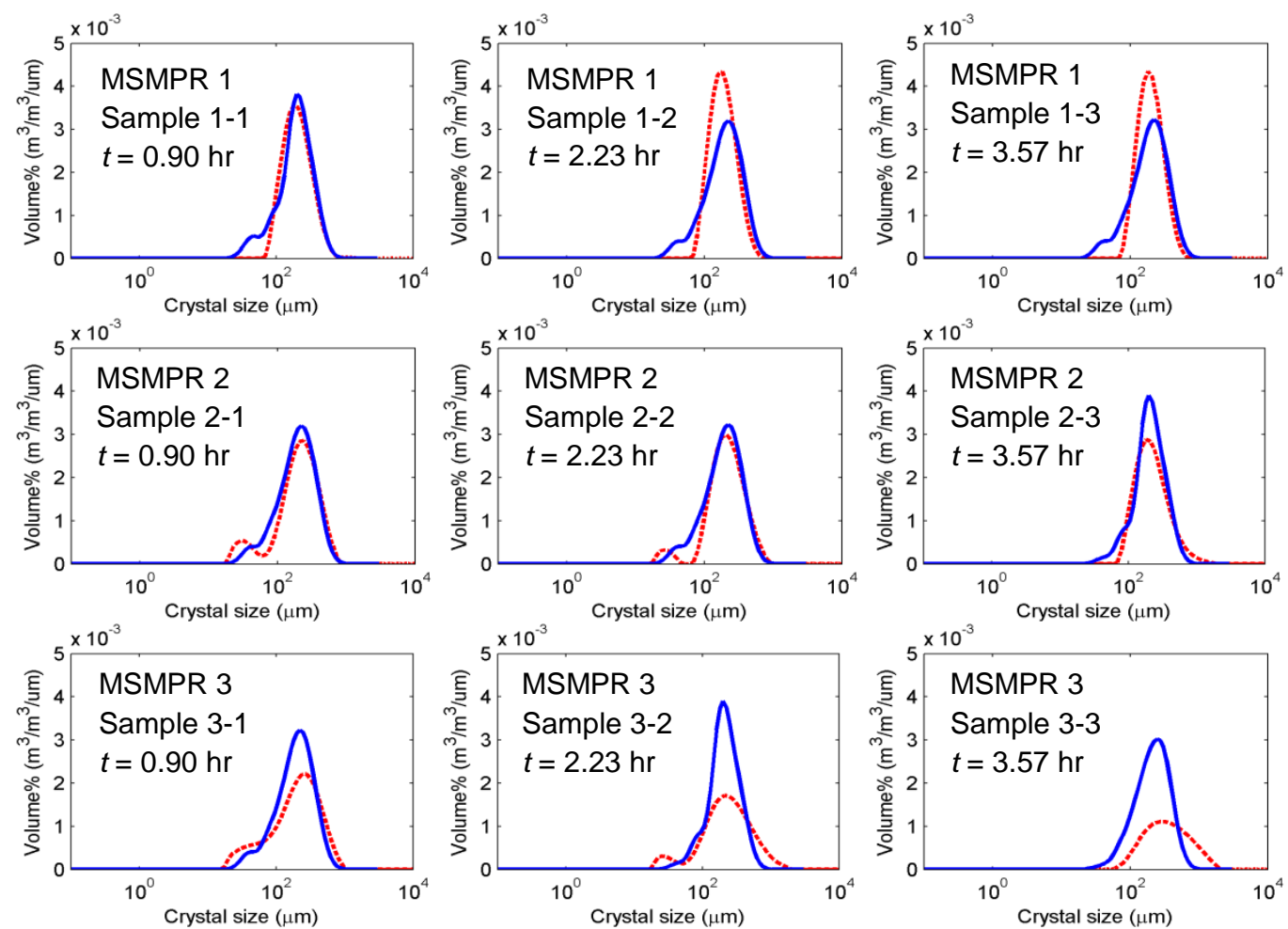

Figure 10 Comparisons of crystal size distributions between predictions and measurements in the three crystallizers for PCS2 experiment (solid line: predicted; dash line: measured).

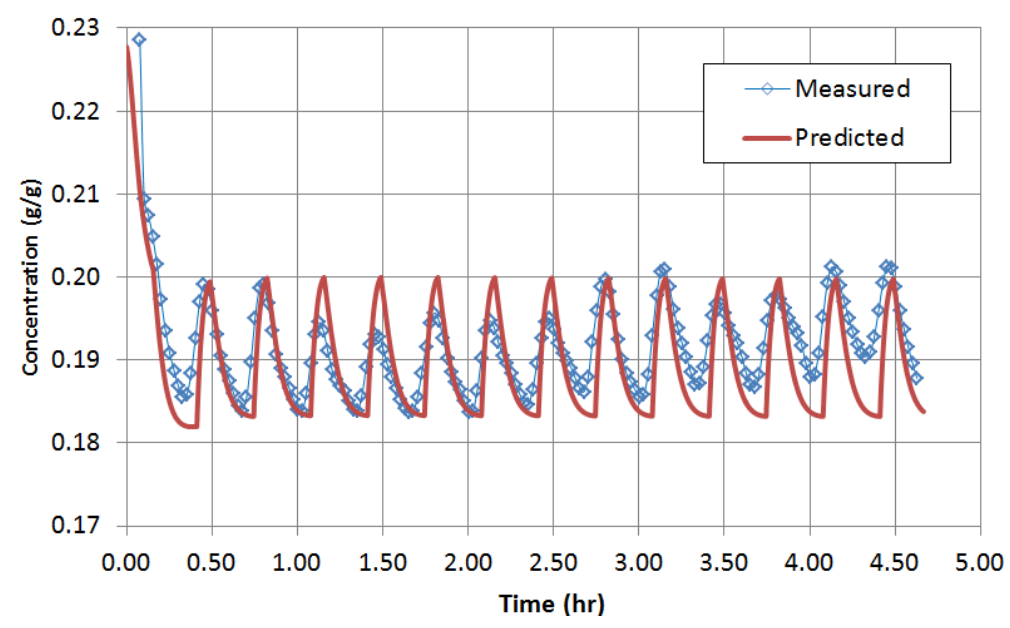

Figure 11 Comparisons of concentration between predictions and measurements for DPSS experiment. 

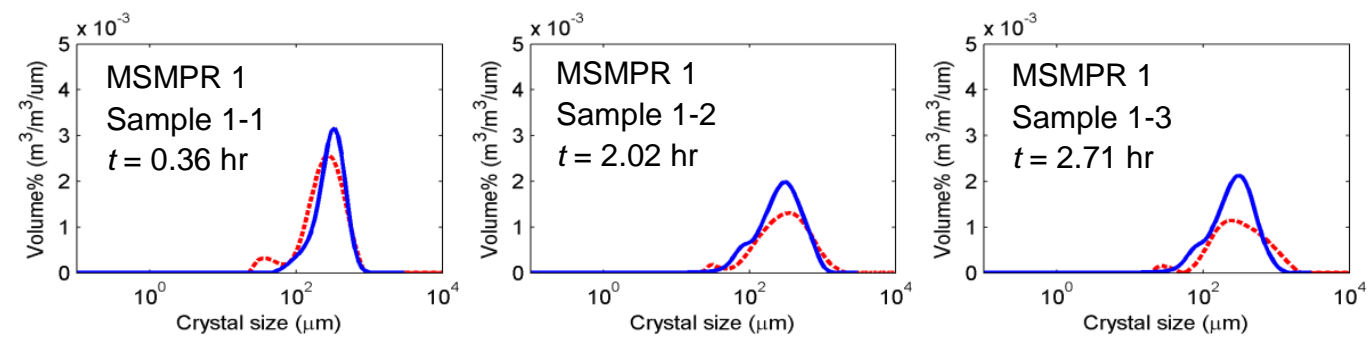

Figure 12 Comparisons of crystal size distributions between predictions and measurements for DPSS experiment (solid line: predicted; dash line: measured).

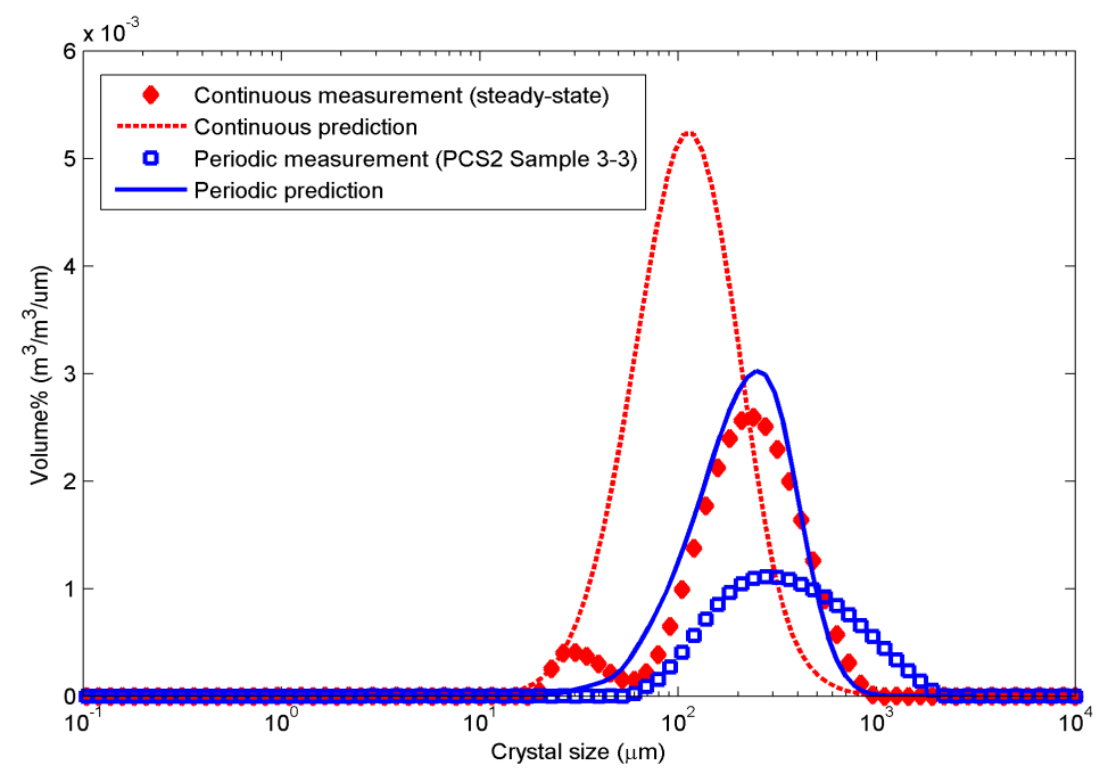

Figure 13 Comparisons of crystal size distribution measurements between continuous flow operation and periodic flow operation with cascaded three-stage MSMPR crystallizers. 


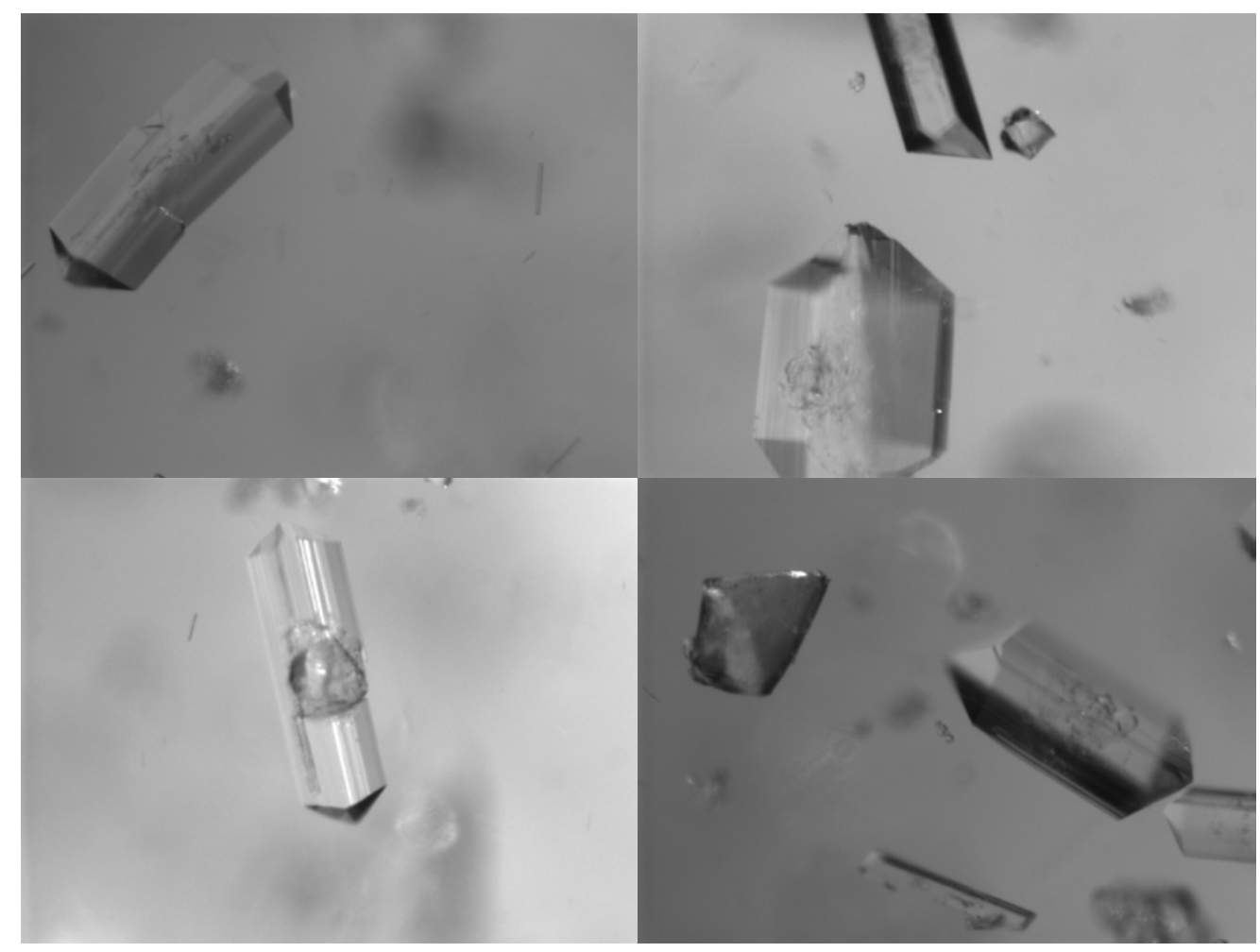

Figure 14 PVM images taken for the last stage crystallizer MSMPR3 in PPS2 experiment. 